\title{
Avaliação do teor de fibra em detergente neutro e ácido por meio de diferentes procedimentos aplicados às plantas forrageiras
}

\section{Evaluation of the content of neutral detergent fiber and acid through different procedures applied to forage plants}

\author{
Luiz Juliano Valério Geron ${ }^{1 *}$; Luciano da Silva Cabral ${ }^{2}$; \\ Raquel Joana Trautmann-Machado ${ }^{3}$; Lúcia Maria Zeoula \\ Edimar Barbosa Oliveira ${ }^{5}$; Jocilaine Garcia ${ }^{1}$; Matheus Ribeiro Gonçalves ${ }^{6}$; \\ Rodrigo Penha Soares Aguiar ${ }^{6}$
}

\begin{abstract}
Resumo
Objetivou-se avaliar o teor de fibra em detergente neutro (FDN) e ácido (FDA) dos capins Marandu, Humidicola; Massai e Mombaça obtidos por três procedimentos diferentes, sendo o método convencional (CON), o Filter Bag Technique da Ankom ${ }^{\circledR}$ (FBT) e o adaptado pela EMBRAPA (EMB). As plantas forrageiras foram obtidas de pastagens implantadas a três anos, no período de setembro na região Sudoeste do Mato Grosso. Foram realizadas três baterias (corridas) de cada procedimento (metodologia) para a determinação da FDN e da FDA das diferentes forrageiras. Utilizou-se um delineamento inteiramente casualizado com três repetições de cada forrageira para cada metodologia nas diferentes baterias. A análise estatística das variáveis estudadas foi interpretada por meio de análise de variância e as diferenças obtidas foram analisadas por meio de teste de Tukey, considerando 5\% de significância. Foi observado que os diferentes procedimentos (CON, FBT e EMB) de determinação do teor FDN não diferiram entre si para as diferentes plantas forrageiras avaliadas, com valores médios de 78,61\% e 74,96\% para os Capins Marandu e Humidicola, respectivamente e de 76,78\% e 73,08\% para os Capins Massai e Mombaça, respectivamente. $\mathrm{O}$ teor de FDA obtido pelos diferentes procedimentos (CON, FBT e EMB) não apresentaram diferença entre si, com valores médios de 50,95\% e 44,86\% para os capins Marandu e Humidicola, respectivamente e de 52,21\% e 51,56\% para os cultivares do gênero Panicum, respectivamente Massai e Mombaça. Assim, conclui-se que os teores de fibra em detergente neutro e ácido dos capins Marandu, Humidicola; Massai e Mombaça podem ser determinados pelo procedimento adaptado pela EMBRAPA, uma vez que este não diferiu em relação a metodologia convencional e a do Filter Bag Technique da Ankom ${ }^{\circledR}$, além de apresentar menor gasto de reagentes e consequentemente menor custo.
\end{abstract}

Palavras-chave: Carboidrato, celulose, fibra alimentar, forrageiras

\footnotetext{
Abstract

This study aimed to evaluate the content of neutral detergent fiber (NDF) and acid (FDA) of Marandu, Humidicula; Massai; Mombaça grass obtained by three different procedures with the conventional

${ }^{1}$ Profs. Drs. da Universidade do Estado de Mato Grosso, UNEMAT, Pontes e Lacerda, MT. E-mail: ljgeron@yahoo.com.br; jo@ unemat.br

2 Prof. Dr. da UFMT, Cuiabá, MT. E-mail: cabralls@ufmt.br

${ }^{3}$ Prof ${ }^{\text {a }}$ M.e da UNEMAT, Pontes e Lacerda, MT. E-mail: raquel trautmann@hotmail.com

${ }^{4}$ Prof $^{\mathrm{a}} \mathrm{Dr}^{\mathrm{a}}$ da Universidade Estadual de Maringá, UEM, Maringá, PR. E-mail: 1mzeoula@uem.br

${ }^{5}$ Discente, Bolsista de Iniciação cientifica da UNEMAT, Pontes e Lacerda, MT. E-mail: edimarzoo@hotmail.com

${ }^{6}$ Discentes da UNEMAT, Pontes e Lacerda, MT. E-mail: matheus.ribeiro@zootecnista.com.br; rodrigodapenha@hotmail.com

* Autor para correspondência
} 
method (CON), the Filter Bag Technique Ankom $^{\circledR}$ (FBT) and adapted by EMBRAPA (EMB). The forage plants were obtained in the Southwest region of Mato Grosso in the September; the samples were collected from pastures planted the three years. There were three batteries (runs) for each procedure (method) for the determination of NDF and ADF of different forages. There were realised three batteries (runs) for each procedure (method) for the determination of NDF and ADF of different forages. We used a completely randomized design with three replications for each methodology. Statistical analysis of the variables studied was performed by analysis of variance and the differences obtained were analyzed by Tukey test, considering 5\% significance level. It was observed that the different procedures (CON, FBT and EMB) to determine the content NDF did not differ between them for different forages plants, with average values of $78.61 \%$ and $74.96 \%$ for the Marandu and Humidicula grass, respectively and $76.78 \%$ and $73.08 \%$ for Massai and Mombaça grass, respectively. The ADF content obtained by different procedures (CON, FBT and EMB) showed no difference between them, with average values of $50.95 \%$ and $44.86 \%$ for Marandu and Humidicula grass, respectively and $52.21 \%$ and $51.56 \%$ for Massai and Mombaça grass, respectively. Thus, it is concluded that the content of neutral detergent fiber and acid Marandu, Humidicula; Massai and Mombaça grass can be determined by the procedure adapted by EMBRAPA, since this was not different compared to conventional methodology and the Filter Bag Technique Ankom ${ }^{\circledR}$, besides having a lower waste of reagents and consequently lower cost.

Key words: Carbohydrate, cellulose, dietary fiber, forage

\section{Introdução}

O estudo da composição química e bromatológica dos alimentos é o ponto de partida para o entendimento dos processos fisiológicos responsáveis pela transformação dos compostos complexos até a formação de produtos de origem animal, principalmente em função da disponibilidade de energia e de outros nutrientes (LIMA, 2004). De acordo com Ítavo et al. (2002), há muitos anos, pesquisadores vêm buscando alternativas para determinar o valor nutricinal dos alimentos utilizados nas dietas de ruminantes.

Os alimentos fibrosos, fonte de carboidratos estruturais (hemicelulose e celulose), são os principais substratos energéticos utilizados pelos microrganismos presentes no aparelho digestivo de animais ruminantes (VAN SOEST, 1994; LIMA, 2003).

A fibra alimentar representa a fração dos carboidratos estruturais contidos nos alimentos, que apresentam a digestão lenta ou menos digestível, dependendo da sua composição pode limitar o consumo de matéria seca (MS) e de energia pelo animal, porém para que o animal tenha uma digestão adequada da matéria seca e demais nutriente há necessidade de que a dieta contenha pequena quantidade de fibra e que essa seja de boa qualidade, logo, rica em hemicelulose e pectina (NUSSIO; CAMPOS; LIMA, 2010).

Para a determinação da fibra alimentar pode ser usado os seguintes métodos "fibra bruta (FB)", "fibra em detergente neutro (FDN)" e "fibra em detergente ácido (FDA)" (LIMA, 2003). De acordo com Neumann (2002), a FB vem sendo substituída pela FDN e FDA há cerca de 40 anos pelos pesquisadores. Segundo Bortolassi et al. (2000), o método de determinação de FB foi desenvolvido há mais de um século pela estação experimental de Weende na Alemanha, desde então vem sendo modificada por outros pesquisadores.

O método proposto por Van Soest (1963) para a determinação da qualidade das plantas forrageiras foi baseado na separação das diversas frações dos constituintes químicos nas forrageiras, por meio de reagentes específicos denominados de detergentes. O detergente neutro possibilita a separação do conteúdo celular (fração solúvel), formada por proteínas, carboidratos solúveis e gorduras da parede celular, da fração insolúvel no detergente neutro, a qual é chamada de fibra em detergente neutro (FDN), constituída de celulose, hemicelulose, lignina, proteína danificada pelo calor e matéria mineral (cinzas). 
Pesquisas desenvolvidas por Van Soest (1967), a qual deu continuidade no estudo da qualidade das plantas forrageiras desenvolveu um detergente ácido específico, a fim de solubilizar o conteúdo celular, a hemicelulose e os minerais solúveis, além de uma parte da proteína insolúvel, dando origem a fibra em detergente ácido (FDA), constituída de celulose, lignina, proteína danificada pelo calor e minerais.

A agilidade na obtenção do teor da fibra alimentar por meio da metodologia de Van Soest (1963, 1967) levou a uma rápida aceitação desta metodologia pelos técnicos e pesquisadores. Entretanto, foi constatado que para algumas categorias de alimentos, principalmente os ricos em amido, pectina, taninos e produtos da reação de Maillard, a metodologia de determinação de FDN e FDA, apresentava baixa eficácia, o que gerou algumas modificações de acordo com o tipo de alimento avaliado (VAN SOEST; ROBERTSON; LEWIS, 1991).

A AOAC (1980) aceitou a técnica desenvolvida por Van Soest $(1963,1967)$ para determinar a estimativa dos componentes totais da parede celular. Segundo Bortolassi et al. (2000), a aplicação desta metodologia tornou possível fracionar os componentes da parede celular e estimar alguns macrocomponentes da parede celular isoladamente por diferença matemática entre os resultados das análises de FDN e FDA das plantas forrageiras.

A maioria dos laboratórios de análise de alimentos utiliza o método de determinação de fibra em detergente. Entretanto, existem várias maneiras de avaliar o teor de FDN e de FDA dos alimentos, podendo ser citado o método convencional (VAN SOEST, 1963), modificado por Jeraci, Hernandez e Robertson (1988), o método alternativo da EMBRAPA desenvolvido por Souza et al. (1999) e o método da Filter Bag Tchenique da Ankom ${ }^{\circledR}$ (FBT), de acordo com Ankom ${ }^{\circledR}$ (2012).

De acordo com Berchielli et al. (2001), o método do Filter Bag Technique da Ankom ${ }^{\circledR}$
(FBT), é uma técnica que foi lançada no mercado afim de minimizar a mão de obra, pois alguns dos procedimento que são realizados pelo método convencional proposto por Van Soest (1963) para determinação da FDN e Van Soest (1967) para obtenção do teor de FDA das forrageiras, como as lavagens e filtragens dos cadinhos porosos, podem ser realizados diretamente no aparelho tipo Ankom ${ }^{\circledR}$, por meio da utilização de filtros chamados "F57" (saquinhos). Os alimentos são alocados dentro dos filtros "F57" os quais são fixados em ambientes fechado dentro do aparelho tipo Ankom ${ }^{\circledR}$, o que garante uma boa homogeneização das amostras além de facilitar e agilizar um maior número de amostra por dia em relação ao método convencional de Van Soest (1963) para determinação da FDN e ao método convencional de Van Soest (1967) para determinação da FDA.

Segundo Vinholis et al. (2006), o método de determinação de FDN e FDA adaptada pela EMBRAPA, foi uma metodologia que buscou simplificar os procedimentos analíticos originais, sem alterar os princípios do método convencional de Van Soest (1963) e Van Soest (1967), respectivamente.

Os carboidratos são divididos em duas categorias, de acordo com seus fatores de disponibilidade, podendo ser estruturais e não estruturais esses critérios de divisão estão ligados ao poder de disponibilidade ao animal hospedeiro e aos microrganismos ruminais (VAN SOEST, 1994). Segundo Carvalho, Barbosa e Macdowell (2005), os carboidratos estruturais são a celuloses, a hemicelulose, a pectina e as beta glucanas e os não estruturais, são o amido e os açucares, além disso, a pectina e as beta glucanas são considerados carboidratos estruturais, mas com rápida fermentação semelhantes aos dos carboidratos de reserva.

Os carboidratos estruturais são os principais responsáveis pela qualidade nutritiva dos alimentos, principalmente dos volumosos, devido a parede 
celular concentrar de 30 a $80 \%$ da MS das plantas forrageiras, sendo representados pela celulose, hemicelulose e a pectina. Outras substâncias podem estar presentes nos diferentes alimentos, tais como os taninos, o nitrogênio, a lignina, a sílica e etc. A lignina pode estar associada a celulose e a hemicelulose, durante o amadurecimento da planta forrageira ao longo do ano, diminuído a digestibilidade dos componentes nutritivos (ALVES, 2007; MAEDA et al., 2007).

O teor de FDN dos alimentos representa a fração da fibra não solúvel em detergente neutro, este teor de FDN dos alimentos pode ser utilizado por técnicos e produtores de ruminantes para o balanceamento de rações com teores adequados de fibra alimentar. De maneira geral, tanto a qualidade como a quantidade de fibra alimentar presente nas plantas forrageiras, são parâmetros chaves que podem influenciar na ingestão de MS pelos animais, seja ela determinada pela densidade energética ou pelo efeito físico de enchimento do rúmen que a fibra alimentar pode causar nos animais ruminantes (MACEDO JUNIOR et al., 2007; GERON et al., 2012).

De acordo com levantamento realizado por Valadares Filho et al. (2010), as diferentes forrageiras apresentam composição bromatológica com valores de FDN e FDA expresso na base da MS de $55,26 \%$ e $31,16 \%$, respectivamente para o capim Marandu, de 78,46 e 45,97\%, respectivamente para o capim Humidicola, de $82,57 \%$ e $46,98 \%$, respectivamente para o capim Massai e de $79,99 \%$ e $44,68 \%$, respectivamente para o capim Mombaça.

Desta maneira, o presente estudo objetivou avaliar o teor de fibra em detergente neutro (FDN) e ácido (FDA) dos capins Marandu, Humidicola, Massai e Mombaça, obtidos pelo método convencional (CON) em relação aos métodos do Filter Bag Technique da Ankom $^{\circledR}$ (FBT) e o adaptado pela EMBRAPA.

\section{Material e Métodos}

O experimento foi realizado no Campus Universitário de Pontes e Lacerda, no Laboratório de Análise de Alimentos e Nutrição Animal (LAANA) pertencentes à Universidade do Estado de Mato Grosso - UNEMAT, os quais estão situados a $15^{\circ}$ 19' 05" de latitude Sul e 59 $19^{\circ}$ ' 26" de longitude Oeste e a uma altitude de 295 metros do nível do mar. O clima da região do Vale do Alto Guaporé - MT é classificado como Tropical Continental, alternadamente úmido e seco do tipo Aw segundo Koppen (SEPLAN, 2007). A precipitação média anual é de 1.500 mm (PEREIRA, 2009).

Os alimentos analisados foram a Urochloa brizantha cv. Marandu (capim Marandu), Urochloa humidicola (capim Humidicola), Panicum maximum spp $\mathrm{x}$ Panicum infestum (capim Massai) e Panicum maximum cv. Mombaça (capim Mombaça), as quais caracterizam algumas das forrageiras utilizadas na região sudoeste do estado de Mato Grosso. Esses alimentos foram coletados em uma propriedade no município de Pontes e Lacerda - MT, no período da seca (mês de setembro de 2012), em pastagens com três anos de implantação. Foram realizadas as coletas da forragem com o auxílio de um quadrado de ferro com diâmetro de $1 \mathrm{~m}^{2}$, aonde foi lançado sob a área da pastagens em 10 pontos aleatórios afim de obter amostra representativa das forrageiras. As amostras foram cortadas entre 5 a $8 \mathrm{~cm}$ de altura do solo, para o gênero Urochloa e Panicum, respectivamente, sendo misturadas em seguida para formar uma amostra composta (média) relativa de cada pastagem de diferente forrageira.

As amostras das plantas forrageiras foram picadas de forma que o comprimento das partículas tivessem aproximadamente 5 a $10 \mathrm{~cm}$, com auxílio de uma tesoura, para facilitar o processo de présecagem. Em seguida foram pesadas e colocadas em estufa com circulação força de ar quente de $55 \pm 5^{\circ} \mathrm{C}$ por 72 horas (SILVA; QUEIROZ, 2002). 
Após a pré-secagem os alimentos estudados foram novamente homogeneizado, para depois passarem pelo processo de moagem em moinho willer (tipo faca) com peneira de 1 milímetro $(\mathrm{mm})$ e armazenados em potes plásticos com tampa.

O delineamento experimental empregado foi inteiramente casualizado para avaliação das diferentes metodologias empregadas para a determinação do teor de FDN e FDA. Foram realizadas três baterias (repetições) diferentes para cada metodologia avaliada, além disso, em cada bateria existia três repetições por planta forrageira estudada.

A análise da composição bromatológica das plantas forrageiras (Tabela 1) foi realizada segundo recomendação de Silva e Queiroz (2002).

Tabela 1. Composição bromatológica dos alimentos estudados.

\begin{tabular}{lcccc}
\hline \multirow{2}{*}{ Nutrientes(\%MS) } & \multicolumn{4}{c}{ Alimentos } \\
\cline { 2 - 5 } & Capim Marandu & Capim Humidicola & Capim Massai & Capim Mombaça \\
\hline MS & 88,25 & 41,65 & 96,80 & 83,21 \\
MO & 6,73 & 6,36 & 7,45 & 10,16 \\
PB & 3,53 & 4,81 & 2,99 & 4,11 \\
EE & 0,55 & 1,31 & 0,80 & 0,89 \\
FB $^{1}$ & 42,48 & 36,50 & 41,96 & 42,62 \\
FDN & 77,80 & 74,60 & 76,30 & 73,00 \\
FDA & 53,10 & 45,62 & 52,45 & 53,27 \\
ENN & 46,71 & 51,01 & 46,81 & 42,21 \\
CNE & 11,39 & 12,91 & 12,47 & 11,84 \\
CHT $^{4}$ & 89,19 & 87,51 & 88,76 & 84,83 \\
MN $^{5}$ & 88,25 & 41,65 & 96,80 & 83,21 \\
NDT $^{5}$ & 51,67 & 53,87 & 52,71 & 54,98 \\
\hline
\end{tabular}

${ }^{1} \mathrm{FB}$ foi obtido pela equação do NRC (1996) que estima a partir do FDN onde: FB = FDA*0,8.

${ }^{2} \mathrm{ENN}$ foi obtido a parti da equação $(\mathrm{ENN}=100-\{\mathrm{MM}+\mathrm{EE}+\mathrm{FB}+\mathrm{PB}\})$ pelo método de Weende descrito por Silva; Queiros $(2002)$. ${ }^{3} \mathrm{CNE}$ Os carboidratos não estruturais (CNE) dos alimentos estudados foi estimados pela fórmula descrita por Sniffen, O’Condor e Van Soest (1992): CNE $=\mathrm{MO}-(\mathrm{PB}+\mathrm{EE}+\mathrm{FDN})$.

${ }^{4} \mathrm{CHT}$ A determinação dos carboidratos totais $(\mathrm{CHT})$ dos alimentos foi obtida pela equação $\mathrm{CHT}=\mathrm{MO}-[\mathrm{EE}+\mathrm{PB}]$ de acordo com Sniffen, O’Condor e Van Soest (1992).

${ }^{5} \mathrm{NDT}$ O teor de nutrientes digestíveis totais (NDT) dos alimentos volumosos frescos foi obtidos pela equação proposta por Chandler (1990) citado no NRC (1996): NDT=105,2 - (0,68*\%FDN).

Fonte: Elaboração dos autores.

O teor de fibra em detergente neutro (FDN) e da fibra em detergente ácido (FDA) das plantas forrageiras foi obtido pelo método convencional descrito por Van Soest, (1963) e Van Soest (1967), respectivamente. Os reagentes necessários para preparar um litro do detergente neutro pelo método de Van Soest (1963) foram: um litro de água destilada; 30,0 g de sulfato de sódio; 18,61 g de EDTA sal dissódico; 6,81 g de borato de sódio hidratado; 4,56 $\mathrm{g}$ de fosfato ácido de sódio anidro e $10 \mathrm{~mL}$ de trietileno glicol, não foi utilizada a enzima alfa amilase termo lábil devido os alimentos volumosos apresentarem baixo teor de amido. Para o preparo do detergente ácido (um litro) pelo método de Van Soest (1967) foram utilizados: $20 \mathrm{~g}$ de brometo-cetil-trimetilamônio e 27,7 mL de ácido sulfúrico (96-98\% de pureza).

Para a determinação da FDN e da FDA pelo método convencional de Van Soest $(1963,1967)$, respectivamente, foi utilizado $1,0 \mathrm{~g}$ de amostra 
condicionada em copos de vidro com capacidade $600 \mathrm{~mL}$ proveniente do digestor de fibra modelo MA- 455 Marconi $^{\circledR}$, adicionando-se $100 \mathrm{~mL}$ da solução detergente neutro ou detergente ácido, respectivamente. A solução contendo as amostras permaneceu em fervura durante 60 minutos a $100^{\circ}$ $\mathrm{C}$, em seguida o conteúdo foi filtrado em cadinho filtrante com porosidade de 50 a $150 \mu \mathrm{m}-\mathrm{n}^{\circ} 2$. Após a filtragem do detergente neutro ou ácido foi adicionado $20 \mathrm{~mL}$ de acetona dentro de cada cadinho e filtrado com auxílio de bomba a vácuo. Os cadinhos de vidro foram acondicionados na estufa a $105^{\circ} \mathrm{C}$ por oito horas para obtenção do resíduo com peso constante.

Ao final destes procedimentos os cadinhos de vidro filtrantes com resíduo (FDN ou FDA) foram colocados em forno mufla e permaneceram nele por quatro horas com temperatura de $470^{\circ} \mathrm{C}$, para queima da matéria orgânica e consequente limpeza da pedra porosa. Em seguida os cadinhos foram mergulhados em solução sulfocrômica para limpeza do resíduo inorgânico por 2 horas. Posteriormente os cadinhos foram lavados com água corrente e testados quanto a sua capacidade de filtração na bomba a vácuo.

Para o método do Filter Bag Technique da Ankom $^{\circledR}($ FBT) utilizou-se $0,5 \mathrm{~g}$ da amostra das diferentes plantas forrageiras, as quais foram acondicionadas dentro do filtro F57, sendo este posteriormente lacrado a quente com utilização de seladora. Os filtros F57 lacrados com as amostras foram acondicionados com o detergente neutro ou com o detergente ácido, obtidos pelo método convencional de Van Soest $(1963,1967)$, respectivamente, e alocados no determinador de fibra modelo TE-149 Tecnal $^{\circledR}$ semelhante ao Fiber Analyzer-Ankom ${ }^{220}$. Foi utilizado aproximadamente $2.300 \mathrm{~mL}$ da solução detergente (neutro ou ácido) para cada bateria com capacidade de 30 filtros F57. Os filtros F57 ficaram em fervura durante 60 minutos e após este tempo procedeu quatro lavagens com água destilada em fervura por 10 minutos cada e em seguida os filtros foram retirados do determinador de fibra e lavados com acetona para serem alocados na estufa a $105^{\circ} \mathrm{C}$ por oito horas, para posterior obtenção do resíduo (FDN ou FDA, respectivamente).

$\mathrm{Na}$ execução do método alternativo da EMBRAPA para determinação da FDN e FDA desenvolvido por Souza et al. (1999), foi utilizado o detergente neutro e ácido conforme o método convencional de Van Soest (1963, 1967), respectivamente. Foi utilizado o tubo de digestão de proteína (25’250 $\mathrm{mm})$, no qual foi alocado 0,35 g de amostra seca ao ar e adicionado $35 \mathrm{~mL}$ da solução detergente neutro ou ácido em cada tubo, respectivamente para determinação da FDN ou FDA. Para a determinação da FDN foi adicionado em cada tubo 0,35 g de $\mathrm{Na}_{2} \mathrm{SO}_{4}$ (sulfito de sódio anidro), levado ao bloco digestor com esferas de vidro (com diâmetro com aproximadamente 25 $\mathrm{mm}$ ) para que os vapores provenientes da fervura do detergente se condensassem evitando a perda de solução, esta fervura com volume constante durou por 60 minutos com o bloco digestor programado para $125^{\circ} \mathrm{C}$.

Após os 60 minutos de fervura o conteúdo dos tubos foram transferidos para cadinhos filtrantes previamente limpos e secos em estufa a $105^{\circ} \mathrm{C}$, a filtragem foi realizada com auxílio de bomba a vácuo. O resíduo foi lavado três vezes com água destilada fervente, até não ser mais observada a presença de espuma dentro do cadinho filtrante. Em seguida cada cadinho foi lavado duas vezes com aproximadamente $40 \mathrm{~mL}$ de acetona e acondicionados em estufa a $105^{\circ}$ C por aproximadamente oito horas para obtenção dos resíduos (FDN ou FDA), após resfriarem a temperatura ambiente dentro de dessecadores estes foram pesados em balança analítica de precisão.

A percentagem da fibra em detergente neutro (FDN) ou ácido (FDA) na base da MS foi obtida por diferença entre as pesagens, FDN ou FDA $(\%)=[(\mathrm{C}$ - B) x 100]/A, em que A foi o peso da amostra em grama, $\mathrm{B}$ o peso do recipiente (cadinho de vidro ou filtro F57) e $\mathrm{C}$ o peso do recipiente mais o resíduo (FDN ou FDA). 
As análises estatísticas das variáveis estudadas foram interpretadas no Sistema de Análises Estatísticas e Genéticas (SAEG) por meio de análise de variância (UNIVERSIDADE FEDERAL DE VIÇOSA, 1997). As diferenças obtidas para as variáveis estudadas (metodologias para determinação da FDN e FDA) das diferentes plantas forrageiras foram avaliadas por meio de teste de
Tukey considerando 5\% de significância.

\section{Resultados e Discussões}

O teor de fibra em detergente neutro (FDN) para o capim Marandu, Humidicola, Massai e Mombaça (Tabela 2) não apresentou diferença $(p>0,05)$ entre as metodologias avaliadas (CON, FBT e EMB).

Tabela 2. Teor de fibra em detergente neutro (FDN) e fibra em detergente ácido (FDA) dos alimentos volumosos obtidos pelas diferentes metodologias laboratoriais (metodologia convencional -CON; do Filter Bag Technique da Ankom $^{\circledR}$ - FBT e pela metodologia adaptado pela EMBRAPA - EMB).

\begin{tabular}{|c|c|c|c|c|}
\hline \multirow[t]{2}{*}{ Variável } & \multicolumn{3}{|c|}{$\begin{array}{l}\text { Diferentes métodos de determinação de fibra em detergente neutro } \\
\text { (FDN) e ácido (FDA) }\end{array}$} & \multirow[t]{2}{*}{$\% \mathrm{CV}$} \\
\hline & $\mathrm{CON}$ & FBT & EMB & \\
\hline \multicolumn{5}{|c|}{ Teor de fibra em detergente neutro - FDN } \\
\hline Capim Marandu & $77,80 \mathrm{a}$ & $80,36 \mathrm{a}$ & $77,68 \mathrm{a}$ & 0,93 \\
\hline Capim Humidicula & $74,60 \mathrm{a}$ & $75,51 \mathrm{a}$ & $74,78 \mathrm{a}$ & 1,97 \\
\hline Capim Massai & $76,30 \mathrm{a}$ & $77,83 a$ & $76,21 \mathrm{a}$ & 0,69 \\
\hline Capim Mombaça & $72,99 a$ & $73,39 a$ & $72,86 a$ & 1,00 \\
\hline \multicolumn{5}{|c|}{ Teor de fibra em detergente ácido-FDA } \\
\hline Capim Marandu & $53,10 \mathrm{a}$ & $48,62 \mathrm{a}$ & $51,14 \mathrm{a}$ & 1,69 \\
\hline Capim Humidicula & $45,62 \mathrm{a}$ & $44,29 \mathrm{a}$ & $44,68 \mathrm{a}$ & 0,63 \\
\hline Capim Massai & $52,45 \mathrm{a}$ & $52,43 a$ & $51,76 \mathrm{a}$ & 1,19 \\
\hline Capim Mombaça & $53,28 \mathrm{a}$ & $49,90 \mathrm{a}$ & $51,50 \mathrm{a}$ & 2,22 \\
\hline
\end{tabular}

Letras diferentes nas linhas apresentam significância a 5\% $(\mathrm{p}<0,05)$ pelo teste de Tukey para as metodologias de determinação da FDN e FDA dos alimentos.

Fonte: Elaboração dos autores.

Foi observada uma amplitude de 3,34\%, para o teor de FDN do capim Marandu, obtido pelo método $\operatorname{FBT}(80,36 \%)$ em relação ao método da EMB (77,68\%), porém esta variação não apresentou diferença significativa. Para o capim Humidicola foi observado que a maior amplitude no teor de FDN $(1,20 \%)$ se deu entre o método FBT $(75,51 \%)$ e o da CON $(74,60 \%)$.

Para o teor de FDN do capim Massai e Mombaça foi observado que o método do FBT apresentouse $2,08 \%$ e $0,72 \%$ acima do valor obtido para o método EMB, mas esta variação nos resultados obtidos não foi significativa, possibilitando a utilização de qualquer uma das três metodologias para a obtenção do teor de FDN das plantas forrageiras avaliadas.

Da mesma maneira, estudo realizado por Bortolassi et al. (2000), ao compararem a metodologia convencional (CON) e a Filter Bag Technique da Ankom (FBT) para o teor de FDN do feno de tifiton 85 , feno de aveia e silagem de milho não observaram diferença $(\mathrm{p}<0,05)$ entre as metodologias com valor de $80,05 \%$ e $79,23 \%$ para feno de tifiton 85 ; de $74,61 \%$ e $74,87 \%$, para feno de aveia e de $57,93 \%$ e $58,58 \%$, para silagem de milho, respectivamente. 
No estudo realizado por Berchielli et al. (2001), para avaliar o teor de fibra em detergente neutro (FDN) de alimentos volumosos (cana-de-açúcar, capim braquiária e silagem de milho) pelo método Ankom (FBT) e CON, não constatou diferença $(p>0,05)$ entre as metodologias. Os valores de FDN obtidos por Berchielli et al. (2001) para o método CON e FBT foram de 59,40\% e 58,59\% para cana-de-açúcar; $57,47 \%$ e $59,26 \%$ para capim braquiária e $47,35 \%$ e 53,79\% para a silagem de milho, respectivamente, este dados corroboram com o presente estudo indicando que não há diferença entre a metodologia CON e FBT para determinação da FDN em diferentes plantas forrageiras.

Estudo realizado por Bortolassi et al. (2000), para comparar a metodologia convencional (CON) e a Filter Bag Technique da Ankom (FBT) para a determinação do teor de FDA da silagem de milho e do feno de tifiton 85 , não foi observada diferença $(p<0,05)$ entre as metodologias. Os autores observaram teor de FDA obtido pelo método CON e FBT de 42,77 e $45,89 \%$ para silagem de milho e de $54,97 \%$ e $57,65 \%$ para o feno de tifton 85 , respectivamente.

De acordo com relatos de Rocha et al. (2011), ao comparar os teores de fibra em detergente ácido (FDA) e da fibra em detergente neutro (FDN) obtidos pelos métodos de análises (CON e EMB), não observaram diferença $(p>0,05)$ entre as metodologias de determinação da FDN e FDA para o capim Urochoa ssp com valor médio de $73,46 \%$ e $37,65 \%$, respectivamente e para a silagem de milho observaram valor médio de $49,84 \%$ e $23,71 \%$, respectivamente.

Segundo Vinholis et al. (2006), o método alternativo proposto por Souza et al. (1999) - EMB para determinação do teor de FDN e FDA das plantas forrageiras utiliza uma menor quantidade de amostra e reagentes o que possibilita um maior número de análise por dia no bloco digestor em relação ao método convencional (CON) de Van Soest $(1963,1967)$. De maneira geral, o método da
EMB necessita de 0,35 $\mathrm{g}$ de amostra da forragem e $35 \mathrm{~mL}$ de reagente (detergente neutro ou ácido), além de ser possível realizar até 80 amostras por dia com apenas um bloco digestor. Entretanto, o método CON de determinação da FDN e FDA necessita de $0,5 \mathrm{~g}$ de amostra de alimento e 100 $\mathrm{mL}$ de reagente (detergente neutro ou ácido), assim o método EMB possibilita uma economia de até $65 \%$ de detergente neutro ou ácido em relação ao método CON. Estes dados corroboram com o presente estudo onde não foi observada diferença entre as metodologias empregadas para a determinação do teor de FDN e FDA das plantas forrageiras, porém foi observada uma redução no volume do detergente neutro ou ácido com a utilização do procedimento da EMB em relação ao CON e FBT.

Assim, conclui-se que o teor da fibra em detergente neutro (FDN) e ácido (FDA) dos capins Marandu, Humidicola, Massai e Mombaça podem ser determinados pelas diferentes metodologias (método convencional, Filter Bag Technique da Ankom e EMBRAPA) sem alterar o valor final destes componentes químicos. Portanto os pesquisadores e técnicos que realizam a determinação da fibra em detergente neutro e ácido de plantas forrageiras poderão utilizar a metodologia desenvolvida pela EMBRAPA, uma vez que esta apresenta menor gasto de reagentes e consequentemente menor custo operacional.

\section{Agradecimentos}

A Fundação de Amparo à Pesquisa do Estado de Mato Grosso (FAPEMAT) por ter concedido bolsas de iniciação cientifica aos acadêmicos do Curso de Zootecnia. A Universidade do Estado de Mato Grosso (UNEMAT) - Campus de Universitário de Pontes e Lacerda, por ter apoiado e auxiliado no desenvolvimento desta pesquisa cedendo os equipamentos do Laboratório de Análise de Alimentos e Nutrição Animal (LAANA). 


\section{Referências}

ALVES, C. T. Efeitos de diferentes niveis de milho em grãos moídos relação proteina: carboidratos não estruturais em dietas para búfalos sobre o metabolismo no rúmen. 2007. Dissertação (Mestrado em Zootecnia) - Faculdade de Zootecnia e Engenharia de Alimentos. Universidade de São Paulo, Pirassununga.

ANKOM. Frequently asked questions. Wichita: Ankon Tecnology, 2012. Disponível em: <http://www.ankom. com/faqs.html>. Acesso em: 20 maio 2012.

ASSOCIATION OF OFFICIAL ANALYTICAL CHEMISTS - AOAC. Official methods of analysis. $13^{\text {th }}$ ed. Washington: AOAC, 1980.

BERCHIELLI, T. T.; SADER, O. P. A.; TONANI, F. L.; PAZIANI, S. F.; ANDRADE, P. Avaliação da Determinação da fibra em detergente neutro e da fibra em detergente ácido pelo sistema ANKOM. Revista Brasileira de Zootecnia, Viçosa, MG, v. 30, n. 5, p. 15721578, 2001.

BORTOLASSI, R. J.; SANTOS, T. G.; ALCALDE, C. R.; GONÇALVES, G. D.; ZAMBOM, M. A.; FURLAN, A. C. Comparação dos métodos convencional e Filter Bag Technique da Ankom para determinação de fibra em detergente neutro e fibra em detergente ácido. Acta Scientiarum, Maringá, v. 22, n. 3, p. 807-811, 2000.

CARVALHO, F.A. N.; BARBOSA, F. A.; MacDOWELL, L. R. Nutrição de bovinos a pasto. 2. ed. Belo Horizonte: Papelform, 2005. 438 p.

GERON, L. J. V.; MEXIA, A. A.; GARCIA, J.; ZEOULA, L. M.; GARCIA, R. R. F.; MOURA, D. C. Desempenho de cordeiros em terminação suplementados com caroço de algodão (Gossypium hirsutum L.) e grão de milho moído (Zea mays L.). Archives of Veterinary Science, Curitiba, v. 17, n. 4, p. 34-42, 2012.

ÍTAVO, L. C. V.; VALADARES FILHO, S. C.; SILVA, F. F.; VALADARES, R. F. D.; PAULINO, M. F.; ÍTAVO, C. C. B. F.; MORAES, E. H. B. K. Comparação de indicadores e metodologia de coleta para estimativas de produção fecal e fluxo de digesta em bovinos. Revista Brasileira de Zootecnia, Viçosa, MG, v. 31, n. 4, p. 18331839, 2002.

JERACI, J. L.; HERNANDEZ, T.; ROBERTSON, J. B. New and improved procedure for neutral-detergent fiber. Journal of Animal Science, Champaign, v. 66, n. 1, p. 351-358, 1988.

LIMA, M. L. M. Analise comparativa da efetividade da fibra de volumosos e subprodutos. 2003. Tese (Doutorado em Agronomia) - Escola Superior de Agricultura Luiz de Queiroz, Piracicaba.
LIMA, R. F. Fracionamento de carboidratos de concentrados energéticos utilizados na alimentação animal. 2004. Dissertação (Mestrado em Zootecnia) Universidade Federal de Santa Maria, Santa Maria.

MACEDO JÚNIOR, G. L.; ZANINE, A. M.; BORGES, I.; OLALQUIAGA PÉREZ, J. R. O. Qualidade da fibra para a dieta de ruminantes. Ciência Animal, Goiânia, v. 17, n. 1, p. 7-17, 2007.

MAEDA, E. M.; ZEOULA, L. M.; GERON, L. J. V.; BEST, J.; PRADO, I. N.; MARTINS, E. N.; KAZAMA, R. Digestibilidade e características ruminais de dietas com diferentes níveis de concentrado para bubalinos e bovinos. Revista Brasileira de Zootecnia, Viçosa, MG, v. 36, n. 3, p. 716-726, 2007.

NATIONAL RESEARCH COUNCIL - NRC. Nutrient requeriment of beef cattle. 7. ed. Washington: National Academy Press, 1996. 242 p.

NEUMANN, N. Avaliação, composição, digestibilidadee aspectos metabólicos da fibra. In: Seminário apresentado na disciplina bioquímica do tecido animal (VET00036) do programa de pós-graduação em ciências veterinárias da UFRGS. Porto Alegre: UFRGS, 2002. 122 p.

NUSSIO, L. G.; CAMPOS, F. P.; LIMA, M. L. M. Metabolismo de carboidratos estruturais. In: Editores: BERCHIELLI, T. T.; OLIVEIRA, A. V. P.; GISELE, S de. Nutrição de ruminantes. Jaboticabal: Funep, 2010. p. 193-238.

PEREIRA, J. A. Geografia de Mato Grosso. Guiratinga: DBCity, 2009. Disponível em: <http://pt.scribd.com/ doc/30740973/Geografia-de-Mt-Livro1>. Acesso em: 15 maio 2013.

ROCHA, M. K. H. R.; SETZNAGL, G.; SILVA DA, J. M. P.; PEZZATO, L. E. Comparação da fibra em detergente ácido (FDA) e da fibra em detergente neutro (FDN) por diferentes métodos de análises. Botucatu: Faculdade de Medicina Veterinária, 2011. 62 p. (Manual, n. 1).

SECRETARIA DE ESTADO DE PLANEJAMENTO E DESENVOLVIMENTO ECONÔMICO - SEPLAN. Zoneamento sócio econômico e ecológico do estado de Mato Grosso. Cuiabá: SEPLAN, 2007. Disponível em: $<$ www.zsee.seplan.mt.gov.br/divulga $>$. Acesso em: 25 maio 2012.

SILVA, D. J.; QUEIROZ. A. C. Análise de alimentos: métodos químicos e biológicos. 2. ed. Viçosa, MG: UFV. 2002. 178 p.

SNIFFEN, C. J.; O'CONNOR, J. D.; VAN SOEST, P. J. A net carbohydrate and protein system for evaluating cattle diets II. Carbohydrate and protein availability. Journal of Animal Science, Champaign, v. 70, n. 11, p. 3562-3577, 1992. 
SOUZA, G. B.; NOGUEIRA, A. R. A.; SUMI, L. N.; BATISTA, L. A. R. Método alternativo para a determinação de fibra em detergente neutro e detergente ácido. São Carlos: Embrapa Pecuária Sudoeste, 1999. 21 p.

UNIVERSIDADE FEDERAL DE VIÇOSA - UFV/ SAEG. Sistema de análises estatísticas e genéticas Viçosa: UFV, 1997. 150 p. (Manual do usuário).

VALADARES FILHO, S. de C.; MAGALHÃES, K. A.; ROCHA JUNIOR, V. R.; CAPELLE, E. R. Tabelas brasileiras de composição de alimentos para bovinos. 3 . ed. Viçosa, MG:UFV/DZO, 2010. 520 p.

VAN SOEST, P. J. Ecologia nutricional dos ruminantes. 2. ed. Rio de Janeiro:. Constock Publishing Associates. 1994. $476 \mathrm{p}$.

. Development of a comprehensive system of feed analysis and its application to forage. Journal Animal Science, v. 26, n. 1, p. 119-128, 1967.
Use of detergents in the analysis of fibrous feeds. A rapid method for the determination of fiber and lignin. Journal of the Association Official Agricultural Chemists, v. 46, n. 5, p. 829-835, 1963.

VAN SOEST, P. J.; ROBERTSON, J. B.; LEWIS, B. A. Symposium: carbohydrate metodoloy, metabolism, and nutritional implications in dairy cattle. Methods for dietary fiber, neutral detergent fiber, and nonstarch polysaccharides in relation to animal nutrition. Journal of Dairy Science, Madison, v. 74, n. 10, p. 3583-97. 1991.

VINHOLIS, M. M. B.; OSCAR, T.; SOUZA, G. B.; NOGUEIRA, A. R. A.; ODO, P. Avaliação dos impactos econômicos, sociais e ambientais de tecnologias da Embrapa Pecuária Sudeste. 7. Método alternativo de determinação de fibra em detergente ácido e fibra em detergente neutro. São Carlos: Embrapa Pecuária Sudeste, 2006. 27 p. 